\title{
EVALUATING THE AERODYNAMIC IMPACT OF CIRCUMFERENTIALLY GROOVED FAN CASING TREATMENTS WITH INTEGRATED ACOUSTIC LINERS ON A TURBOFAN ROTOR
}

\author{
Richard F. Bozak and Gary G. Podboy \\ NASA Glenn Research Center \\ Cleveland, OH, USA \\ Email: Richard.F.Bozak@nasa.gov and Gary.G.Podboy@nasa.gov
}

\begin{abstract}
NASA is investigating the potential of integrating acoustic liners into fan cases to reduce fan noise, while maintaining the fans aerodynamic performance. An experiment was conducted to quantify the aerodynamic impact of circumferentially grooved fan cases with integrated acoustic liners on a 1.5 pressure ratio turbofan rotor. In order to improve the ability to measure small performance changes, fan performance calculations were updated to include real gas effects including the effect of humidity. For all fan cases tested, the measured difference in fan isentropic efficiency was found to be less than the measurement repeatability for a torque-based efficiency calculation $(\approx 0.2 \%)$, however, an unintended tip clearance difference between configurations makes it difficult to determine if circumferentially grooved fan cases degraded fan performance. Fan exit turbulence measurements showed a $1.5 \%$ reduction in total turbulence intensity between hardwall and circumferentially grooved fan cases in the tip vortex region, which is attributed to a disruption in the formation of the tip leakage vortex. This decrease in fan exit turbulence could potentially lead to a 1-2dB reduction in broadband rotor-stator interaction noise. Reduced aerodynamic performance losses associated with over-the-rotor liners could enable further fan noise reduction.
\end{abstract}

$N$ Rotation Speed, rpm

$p$ Pressure, psia $(k P a)$

$T$ Temperature, ${ }^{\circ} R\left({ }^{\circ} \mathrm{K}\right)$

$\dot{m}$ Mass Flow, $\mathrm{lb} / \mathrm{s}(\mathrm{kg} / \mathrm{s})$

$f$ Frequency, $\mathrm{Hz}$

$h$ Enthalpy, $B T U / \mathrm{lb}(\mathrm{kJ} / \mathrm{kg})$

$P$ Power, $H P(k W)$

$E$ Streamwise Turbulent Energy, $f t^{2} / s(J)$

$\eta \quad$ Isentropic Efficiency, \%

SDR Standard Deviation of the Repeatibility

FPR Fan Total Pressure Ratio

FTR Fan Total Temperature Ratio

ADP Aerodynamic Design Point

TRL Technology Readiness Level

EPNL Effective Perceived Noise Level, dB

\section{NOMENCLATURE}

$M$ Mach Number

$U$ Axial Velocity, $f t / s(\mathrm{~m} / \mathrm{s})$

\author{
Subscripts \\ 0 Stagnation Condition \\ $s$ Isentropic \\ $T$ Temperature Based \\ $\tau$ Torque Based \\ c Corrected to Standard Day \\ $e$ Error
}

This material is declared a work of the U.S. Government and is not subject to copyright protection in the United States.

Approved for public release; distribution is unlimited. 
noise is expected to remain a large contributor to airport noise for advanced subsonic transport aircraft [1]. Over-the-rotor acoustic liners have been shown to reduce sound power level by as much as 4-5dB [2], but have also shown significant aerodynamic performance losses [3]. Acoustic liners installed over-the-rotor were shown to have the potential for substantial system level aircraft noise reduction on a Hybrid Wing Body (0.5 EPNL) [4] and MidFuselage Nacelle (1.6 EPNL) [5] subsonic transport concepts.

NASA has been developing over-the-rotor acoustic liners for about 15 years with varying success. Foam metal liners installed directly over-the-rotor have resulted in an 8-10\% loss in fan efficiency. The inclusion of perforate between the foam metal and rotor reduced this performance loss to $4 \%$, but led to blade tip degradation [3]. The inclusion of circumferential grooves between the rotor and acoustic treatment has been shown to mitigate the performance loss and blade tip degradation [2]. In 2012, an over-the-rotor acoustic liner with integrated circumferential grooves was shown to reduce the fan efficiency loss to less than $1 \%$ [6]. In order to enable the application of over-the-rotor acoustic liners, the fan efficiency loss needs to be eliminated. Therefore, validation of the impact on fan efficiency is required early in the development process at low Technology Readiness Levels (TRLs).

A series of tests were executed to improve the understanding of the acoustic and aerodynamic effects of acoustic casing treatment concepts. Experiments to quantify the acoustic performance included impedance measurements in a Normal Incidence Tube, Grazing Flow Impedance Tube measurements [7], Advanced Noise Control Fan measurements [8], and finally an experiment with treatments installed over a turbofan rotor in an internal flow facility [9]. These tests showed a potential $2-5 \mathrm{~dB}$ reduction in forward propagating in-duct sound power level.

While the acoustic effect on rotor noise has been evaluated, this paper will focus on the aerodynamic performance impacts of these acoustic treatments. In addition to their ability to reduce forward propagating noise, over-the-rotor casing treatments can alter the fan exit turbulence, which could potentially reduce rotor-stator interaction noise. A turbofan rotor experiment investigating the aerodynamic impact of fan casing treatments is described and test results are presented.

\section{EXPERIMENT}

An experiment was conducted in the W-8 Single-Stage Axial Compressor Facility at the NASA Glenn Research Center to evaluate the aerodynamic impact of fan cases containing circumferential grooves and acoustic liners on a 1.5 fan pressure ratio turbofan rotor in a rotor alone configuration. In addition to quantifying the acoustic impact of over-the-rotor liners [9], the aerodynamic impact was quantified with measurements from steady and unsteady fan exit instrumentation.

\section{Internal Flow Facility}

The W-8 Single Stage Axial Compressor facility is an internal flow fan or compressor aerodynamics facility that has traditionally been utilized for measuring and validating rotor performance and stability. A schematic of the facility is shown in Fig. 1. The facility provides up to $7,000 \mathrm{hp}(5220 \mathrm{~kW})$ at up to 21,240 rpm to up to a 22 in $(0.559 \mathrm{~m})$ diameter rotor. For the testing described, an atmospheric inlet was utilized to provide up to 100 $\mathrm{lb} / \mathrm{s}(45.4 \mathrm{~kg} / \mathrm{s})$ to the rotor. Therefore, inlet conditions varied with atmospheric conditions. Flow conditioning screens in the inlet plenum reduce the turbulence intensity at the fan to less than $1 \%$ [10]. Exhaust flow is controlled with a sleeve throttle valve and an atmospheric exhaust system. The facility instrumentation utilized for this test included steady pressure and thermocouple temperature measurements, humidity sensors, shaft torque and speed measurements, and tip clearance sensing.

\section{Test Hardware}

The Source Diagnostic Test fan rotor, designated R4, was utilized for this experiment. The high bypass turbofan rotor is a $1 / 5$ scale model with a 22 in $(0.559 \mathrm{~m})$ diameter and 22 titanium blades. The fan has a design pressure ratio of 1.5 at 12,657 $r m_{c}$. This turbofan rotor was chosen for over-the-rotor treatment testing because of its extensive historical datasets acquired from experiments in the W-8 facility $[6,10]$ and in the 9x15 Low Speed Wind Tunnel $[11,12]$ at NASA Glenn Research Center. A photograph of the R4 fan installed in the W-8 facility with the inlet case removed is shown in Fig. 2.

The previous iteration of circumferentially grooved overthe-rotor acoustic treatments were found to produce an efficiency loss between $0.75 \%$ and $2 \%$. In order to further reduce the performance loss, the circumferential grooves were deepened based on the findings of Bailey [13] and the 'rules of thumb' provided by Hathaway [14]. In addition to the change in the groove design, the experiment was designed to isolate the circumferential groove effect from the acoustic treatment effect by including a circumferentially grooved fan case configuration in addition to the hardwall and acoustically treated fan cases, as shown in Fig. 3. The circumferentially grooved fan cases were fabricated from sheets of G10 fiberglass epoxy laminate which was laser cut to the proper dimensions and stacked axially to create six rows of circumferential grooves. Each groove is 0.25 in (6.4 $\mathrm{mm}$ ) wide by 0.5 in $(13 \mathrm{~mm})$ deep with 0.125 in $(3.2 \mathrm{~mm})$ ribs between the grooves. In addition to the hardwall and grooved only configurations, four different acoustic treatment concepts were installed into the bottoms of the circumferential grooves. These four treatments are denoted Empty Chamber, Thick Perforate, Foam Metal, and Expansion Chamber. Details of these treatments are provided with the acoustic results [9], and crosssections of these treatment concepts are shown in Fig. 4. An unintended tip clearance difference existed between the hardwall 


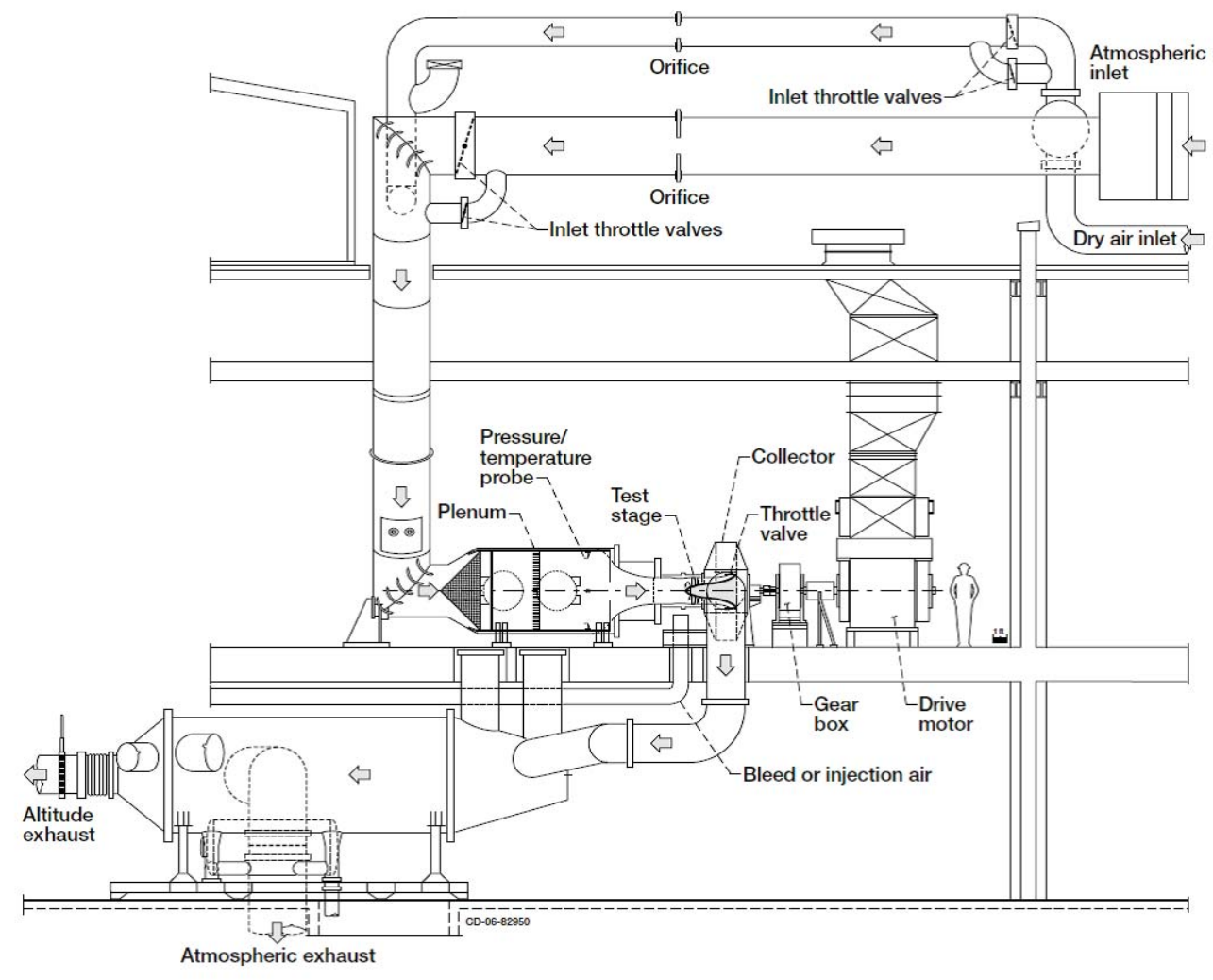

FIGURE 1: SCHEMATIC OF THE W-8 SINGLE STAGE AXIAL COMPRESSOR FACILITY [10].

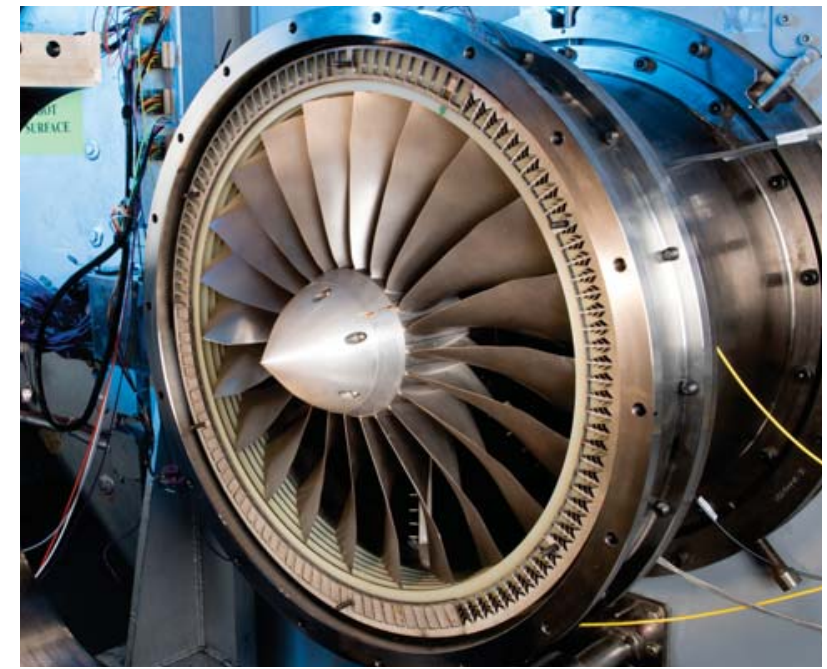

FIGURE 2: R4 TURBOFAN ROTOR INSTALLED IN W-8 WITH TREATMENTS INSTALLED OVER-THE-ROTOR. and grooved fan cases. The mean hot mid-chord tip clearance was measured with tip clearance probes for the hardwall fan case and was found to be $0.040 \mathrm{in}(1.0 \mathrm{~mm})$, while the mean hot midchord tip clearance was $0.020 \mathrm{in}(0.51 \mathrm{~mm})$ for all grooved fan cases.

\section{Instrumentation}

Aerodynamic instrumentation was installed at axial stations denoted in Fig. 5. Inflow conditions are measured in the inlet plenum with four total pressure and total temperature sensors as well as a relative humidity sensor. After the bellmouth contraction, a ring of eight static pressure taps on the outer duct wall were utilized for a mass flow correlation developed by Van Zante et. al. [10]. The rotor inlet (Station 2) was utilized for the measurement of rotor inlet conditions. Finally, the fan exit (Station 12.5, $2.2 \mathrm{in}$. $(55.9 \mathrm{~mm}) \approx 1$ Chord downstream from the fan trailing edge) was utilized to measure fan exit flow profiles. Fan exit total pressure and temperature profiles were each measured with 3 seven-element rakes. Static pressures were measured at this station both on the outer duct and hub. At this fan exit location, a radially traversing actuator was outfitted with either a 


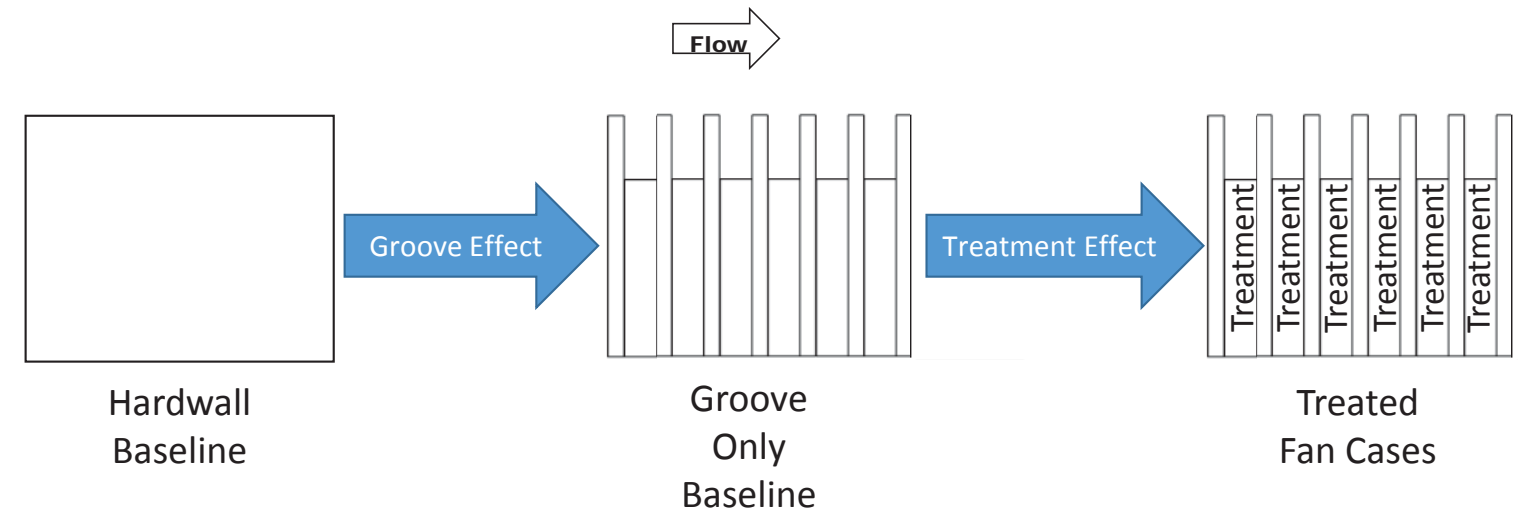

FIGURE 3: HARDWALL AND GROOVED FAN CASE CONFIGURATIONS. FAN CASE RINGS WERE ABOUT 2 IN. (5.1 CM) WIDE BY $1.75 I N .(4.4 C M)$ DEEP.

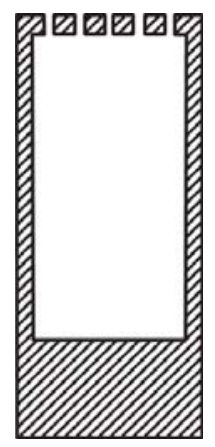

(A)

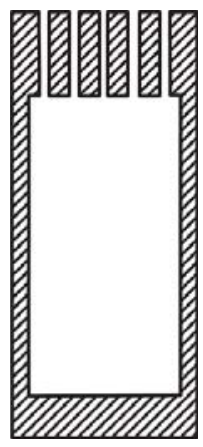

(B)

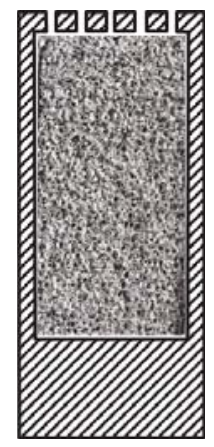

(C)

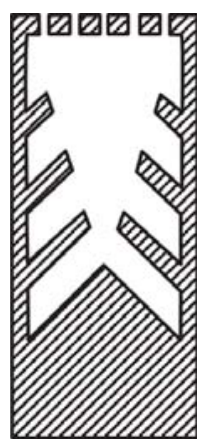

(D)

FIGURE 4: CROSS-SECTIONS OF THE ACOUSTIC TREATMENT CONCEPTS (FLOW DIRECTION IS INTO THE PAGE), (A) EMPTY CHAMBER, (B) THICK PERFORATE, (C) FOAM METAL, AND (D) EXPANSION CHAMBER. SOUND ENTERS THROUGH THE 0.035 IN. (0.89 MM) DIAMETER PERFORATE AT THE TOP.

total pressure and total temperature probe or a 2-component hot film probe. The translating total pressure total temperature probe is shown in Fig. 6(A). Unsteady axial and tangential velocity

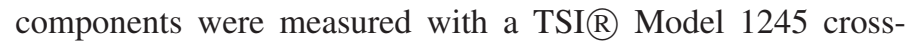
film probe which is shown in Fig. 6(B). In addition to the flow measurements, shaft torque was quantified with a Torquemeters ET2305 torque meter. Since there is a bearing between the torque meter and the rotor, bearing losses were removed by measuring and subtracting the tare torque. This tare torque was quantified at each fan speed by spinning a dummy hub to speed without the rotor installed.

\section{Test Execution}

Testing for each configuration included obtaining aerodynamic rake measurements at nine fan speeds along the nominal operating line as well as speed lines at three speeds [9]. Additionally, total pressure and temperature probe and hot film probe surveys were obtained on the nominal operating line at the three acoustic rating conditions show in Tab. 1. Data were obtained for each fan case configuration by setting the desired set point conditions and acquiring a 10 second average for each steadystate data point. Radial traversing of fan exit probes followed a 48-point profile spanning from the hub to the tip.

\section{FAN PERFORMANCE EVALUATION METHODOLOGY}

The experimental evaluation of fan aerodynamic performance provides validation to computational predictions and enables TRL progression. The primary measure of fan performance is a calculation of the isentropic efficiency as shown in Eqn. 1 , which is dependent on the fan inlet enthalpy $\left(h_{01}\right)$, fan exit enthalpy $\left(h_{02}\right)$, and enthalpy assuming isentropic compression $\left(h_{02 s}\right)$.

$$
\eta_{T}=\frac{h_{02 s}-h_{01}}{h_{02}-h_{01}}
$$

The measurement of isentropic efficiency requires an accurate measurement of fan inlet and exit conditions. In an internal flow fan/compressor facility, such as the W-8 Single Stage Axial Compressor Facility at NASA Glenn Research Center, atmospheric inlet conditions are typically uniform. However, rotor or stage exit conditions may vary radially and circumferentially. Therefore, arrays of total pressure and temperature mea- 


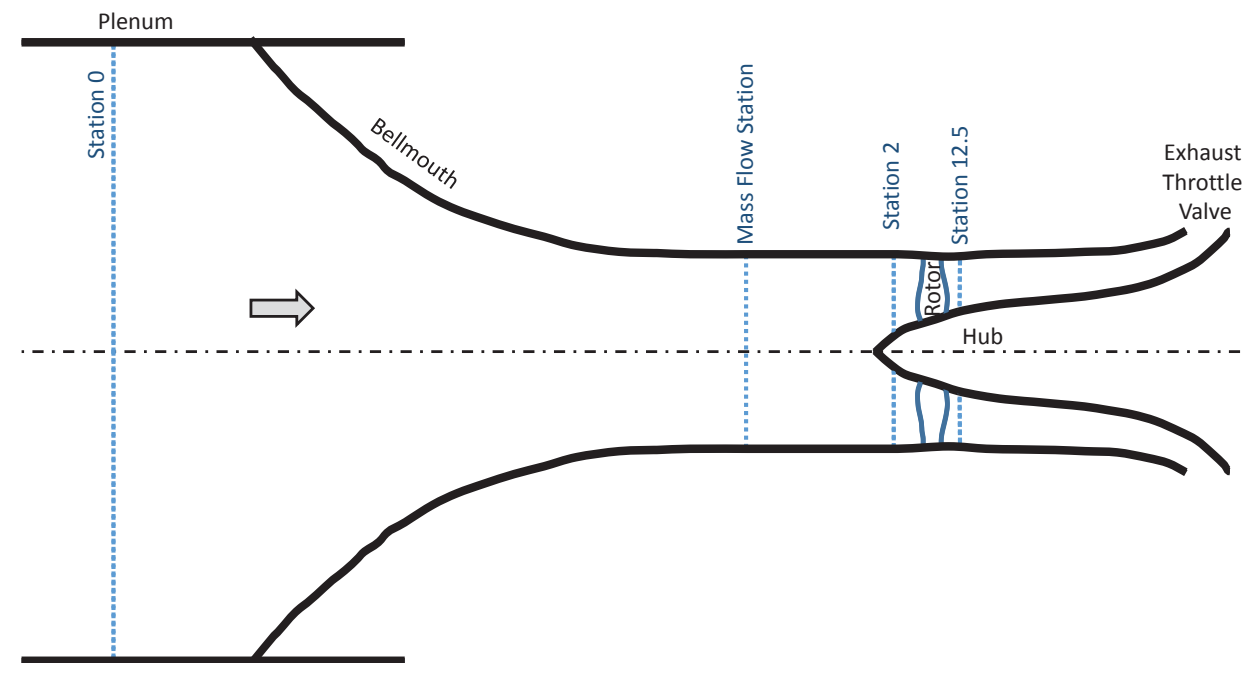

FIGURE 5: ROTOR ALONE STATION DESIGNATIONS.

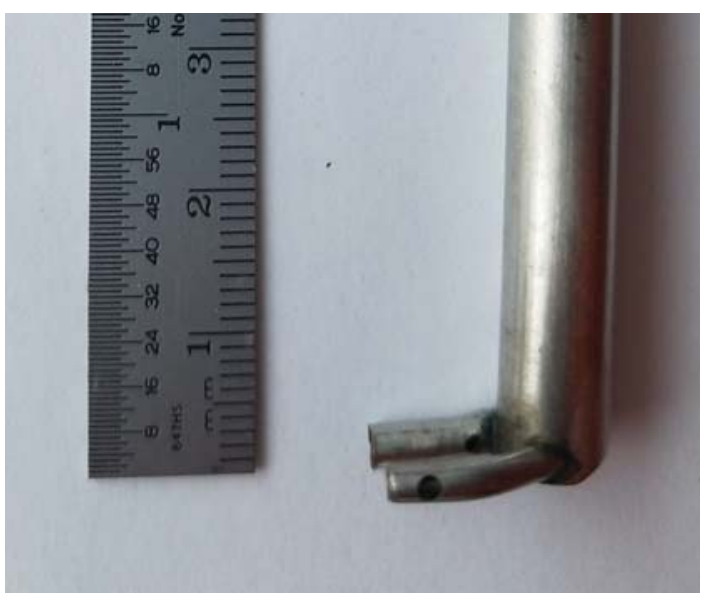

(A)

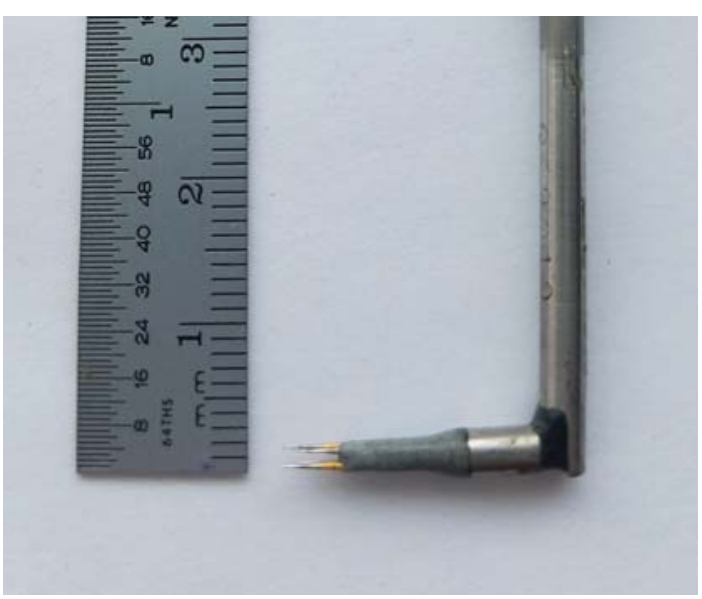

(B)

FIGURE 6: RADIAL TRAVERSING (A) TOTAL PRESSURE AND TOTAL TEMPERATURE AND (B) 2-COMPONENT HOT FILM PROBES.

TABLE 1: SET POINT CONDITIONS AND MEASURED REPEATABILITY.

\begin{tabular}{|c|c|c|c|c|c|c|}
\hline \multirow[b]{2}{*}{ Condition } & \multicolumn{3}{|c|}{ Set Point Conditions } & \multicolumn{3}{|c|}{ Efficiency $(\eta)$ Repeatability, \% } \\
\hline & $\begin{array}{l}\% \text { Fan } \\
\text { Speed }\end{array}$ & $\begin{array}{c}\text { Corrected Fan } \\
\text { Speed, } r p m_{c}\end{array}$ & $\begin{array}{c}\text { Corrected Mass } \\
\text { Flow, } l b / s\end{array}$ & $\begin{array}{l}\text { Single Point } \\
\text { Probe } \mathrm{SDR}_{\eta T}\end{array}$ & $\begin{array}{l}\text { Rake Averaged } \\
\operatorname{SDR}_{\eta T}\end{array}$ & $\begin{array}{l}\text { Torque Based } \\
\operatorname{SDR}_{\eta \tau}\end{array}$ \\
\hline Approach & $61.7 \%$ & 7,809 & 57.8 & $1.7 \%$ & $0.75 \%$ & $0.35 \%$ \\
\hline Cutback & $87.5 \%$ & 11,075 & 83.7 & $1.2 \%$ & $0.52 \%$ & $0.16 \%$ \\
\hline Takeoff & $100.0 \%$ & 12,657 & 97.2 & $0.92 \%$ & $0.52 \%$ & $0.17 \%$ \\
\hline
\end{tabular}


surements are utilized to quantify the exit conditions. Total pressure, total temperature, and relative humidity measurements in the inlet plenum (Station 0) were used to calculate an inlet enthalpy. Fan exit pressures and temperatures (Station 12.5, 2.2 in. $(55.9 \mathrm{~mm})$ downstream from the fan trailing edge) were measured at the fan exit. The calculation of enthalpies from pressures and temperatures was enabled by the incorporation of REFPROP [15] into the data acquisition system. The enthalpies are then used to calculate isentropic efficiency via Eqn. 1.

In addition to the total pressure and total temperature measurements, the W-8 facility utilizes a torque meter to provide an additional measurement of isentropic efficiency that is not dependent on temperature measurement as shown in Eqn. 2.

$$
\eta_{\tau}=\frac{h_{02 s}-h_{01}}{P / \dot{m}}
$$

For experimental facilities with an atmospheric inlet, the use of standard day corrections is essential to obtaining repeatable performance measurements. For axial fans and compressors, corrected shaft speed, $N$, and corrected mass flow, $\dot{m}$, are utilized as set points to ensure repeatable fan performance measurements [16]. In order to ensure accurate calculations of enthalpies for Eqns. 1 and 2, standard day corrections included the effect of humidity following the methods shown by Berdanier et al. [17]. These humidity corrections were used to ensure repeatable performance measurements.

\section{RESULTS}

The aerodynamic impact of the fan case configurations is evaluated by examining the differences in each type of performance measurement between the fan case configurations. Tip clearance sensitivity measurements on this rotor by Hughes et. al. [12] showed a loss in adiabatic efficiency of up to $1 \%$ associated with a 0.020 in $(0.51 \mathrm{~mm})$ increase in tip clearance at the $100 \%$ fan speed. However, when measurements of fan efficiency are compared against prior results from Van Zante [10], the fan appears to be performing at about the same or slightly higher efficiency, as shown in Fig. 7. In this figure fan efficiencies are compared for the temperature rake based (Eqn. 1) and torque based (Eqn. 2) efficiency calculations for subsets of speed lines at the acoustic rating conditions in Tab. 1 as well as along the nominal operating line. The dashed lines show a repeat of the measurements after the fan case was removed and reinstalled later in the test. There is a large spread in the temperature based efficiencies at low speed conditions while the torque based efficiency measurements remain remarkably repeatable for all conditions.

\section{Repeatability}

The experiment was designed to evaluate the impact of different fan case configurations on the aerodynamics of a turbofan rotor. Therefore, the delta performance measurement was prioritized over the measure of absolute performance. In an effort to reduce potential sources of systematic error, the instrumentation and fan duct hardware was left in place when changing fan cases as much as possible. The remaining systematic and random errors were quantified by measuring the ability to repeat each type of measurement. This repeatability quantification included repeats of each type of measurement at each fan condition, but the fan case installation was only repeated twice. The repeatability was quantified by taking the standard deviation of repeat of the efficiency calculated from a single point pressure/temperature probe measurement, averaged pressure and temperature rake measurements, and the torque based efficiency calculation. The standard deviation of this repeatability measurement, termed SDR, is calculated from 48 steady-state data points which are each a 10 second average. The SDR for each of the three types of measurement at each of the conditions is shown in Tab. 1.

\section{Aerodynamic Performance Impact}

The aerodynamic performance impact of fan case configurations containing circumferential grooves and acoustic treatments are evaluated by comparing measured fan efficiencies along a subset of the speed lines at the conditions in Tab. 1. These speed line comparisons are shown in Fig. 8 for both the temperature based and torque based efficiency measurements. While the temperature based efficiency shows a potential loss of about $4 \%$ at $61.7 \%$ fan speed, this is on the order of the measurement repeatability. The torque based efficiency shows no significant difference for any of the fan case configurations tested.

Details of the fan exit profile were measured with a radially traversing total pressure and temperature probe for each fan case configuration. The fan efficiency for each of these radial locations was calculated and plotted in Fig. 9. While there is some variation in the flow profiles, this is believed to be within the measurement repeatability.

The sensitivity of fan adiabatic efficiency to tip clearance for this fan was measured by Hughes et. al. [12]. A 0.020 in $(0.51 \mathrm{~mm})$ reduction in tip clearance was found to increase fan adiabatic efficiency by up to $0.5 \%$. A $0.5 \%$ loss in fan adiabatic efficiency from the grooved fan cases could be counteracted by this $0.5 \%$ increase due to the tip clearance difference. Therefore, it is difficult to separate the effects of circumferential grooves and tip clearance from this experiment.

\section{Fan Exit Turbulence Impact}

Hot film probes were used to acquire unsteady velocity measurements in the rotor wake flow in order to determine the impact 
of the different casing treatments on the fan exit turbulence at $61.7 \%$ fan speed. An increase in fan exit turbulence level would be expected to result in increased broadband rotor-stator interaction noise. At higher fan speeds, turbulence measurements were corrupted by excessive probe vibration.

Figure 10(A) shows a comparison of the radial distribution of total turbulence intensity (computed from axial and tangential velocity components) measured for each of the six fan case configurations at $61.7 \%$ fan speed. The dashed lines separate the spanwise fan exit flow field into three regions; the casing boundary layer region, the tip vortex region, and the wake region. Over the entire tip vortex region, between $80 \%$ and $95 \%$ span, the total turbulence intensity for the smooth, hardwall configuration was measured to be about $1.5 \%$ higher than the grooved fan cases. Figure 10(B) shows a comparison of turbulent energy spectra between the hardwall and groove only configurations in the middle of the tip vortex region at $87 \%$ span for the $61.7 \%$ fan speed. This comparison shows significantly lower turbulent energy over the low frequency region of the turbulent spectrum (under $10 \mathrm{kHz}$ ) for the circumferentially grooved fan case relative to the smooth, hardwall fan case. The spectra collapse at higher frequencies where the turbulent energy is dissipated. Outside of the tip vortex region, the turbulent energy spectra for the hardwall and groove only fan cases are identical.

Total turbulent velocity contours are plotted in Fig. 11 to illustrate the spatial dependence of the fan exit turbulence. These plots show that the turbulence associated with the hardwall configuration is higher and extends further inboard from the case compared to the grooved configurations and all grooved configurations performed the same.

As mentioned earlier, the hardwall configuration exhibited a larger mid-chord tip clearance at $100 \%$ speed $(0.040 \mathrm{in} .(1.0 \mathrm{~mm})$ vs. $0.020 \mathrm{in} .(0.51 \mathrm{~mm})$ for the grooved $)$, which along with the casing configurations could impact the fan exit turbulence. Previous data obtained on this rotor, however, suggests that the change in turbulence level noted here may not be due to the larger tip gap associated with the hardwall configuration. Laser Doppler Velocimeter measurements reported by Hughes et. al. [12] made with this rotor operating at $61.7 \%$ speed in the hardwall configuration showed little change in the turbulence level downstream of the blade tips when the tip clearance was changed by 0.040 in $(1.0 \mathrm{~mm})$. Consequently, the change in geometry (grooved vs. smooth) may be responsible for the change in turbulence. Radial flows into and out of circumferential grooves have been shown to disrupt the formation of a conventional tip leakage vortex [18], which can potentially reduce the turbulence intensity in the tip vortex.

The reduction in turbulence intensity could potentially lead to a reduction in rotor-stator interaction noise. The impact is estimated by assuming that the sound pressure level from the turbulence-stator interaction scales with the turbulent intensity squared as found in Amiet's model for turbulence-airfoil interac- tion [19]. The reduction in turbulence intensity in the tip vortex region would lead to a $1-2 \mathrm{~dB}$ reduction in sound pressure level. The importance of turbulence-stator interaction noise in the tip vortex region to the total propulsion system noise is dependent on the propulsion cycle. Extrapolating this effect further requires a more detailed assessment.

\section{CONCLUSIONS}

An experiment was conducted in the W-8 Single Stage Axial Compressor facility at NASA Glenn Research Center to quantify the aerodynamic impact of circumferentially grooved fan cases with integrated acoustic liners. Fan case configurations included a hardwall baseline, a circumferentially grooved baseline, and four acoustic treatments installed at the bottoms of circumferential grooves. Aerodynamic performance was measured with steady-state aerodynamic instrumentation and shaft torque measurement, while the unsteady aerodynamic impact was measured with a 2-component hot film probe.

The difference in fan adiabatic efficiency between all of the configurations tested was within the measurement repeatability of about $0.2 \%$ for torque-based efficiency calculations. However, a tip clearance difference between the hardwall and grooved configurations of $0.020 \mathrm{in}$. $(0.51 \mathrm{~mm})$ could have counteracted a $0.5 \%$ loss in fan adiabatic efficiency from the circumferential grooves. Therefore, it is difficult to separate the effects of circumferential grooves and tip clearance from this experiment.

A $1.5 \%$ reduction in fan exit turbulence intensity was found with the circumferentially grooved fan cases relative to the hardwall fan case over the tip vortex region. This reduction is not believed to be due to the $0.020 \mathrm{in}$. $(0.51 \mathrm{~mm})$ difference in tip clearance between the fan cases. The grooves are believed to have disrupted the traditional tip vortex formation resulting in reduced turbulence intensity.

The acoustic impact of these over-the-rotor acoustic liners was shown to reduce forward propagating noise by $2-5 \mathrm{~dB}$ sound power level [9]. In addition, the reduction in fan exit turbulence intensity could potentially reduce broadband rotor-stator interaction noise by $1-2 \mathrm{~dB}$. Advanced aeroacoustic liners, such as over-the-rotor casing treatments, require continued development to optimize noise reduction while maintaining aerodynamic performance.

\section{ACKNOWLEDGMENTS}

This work was supported by the Advanced Air Transport Technology Project of NASA's Advanced Air Vehicles Program. The authors would like to thank the W-8 Single Stage Axial Compressor Facility staff for their efforts executing this test activity. 


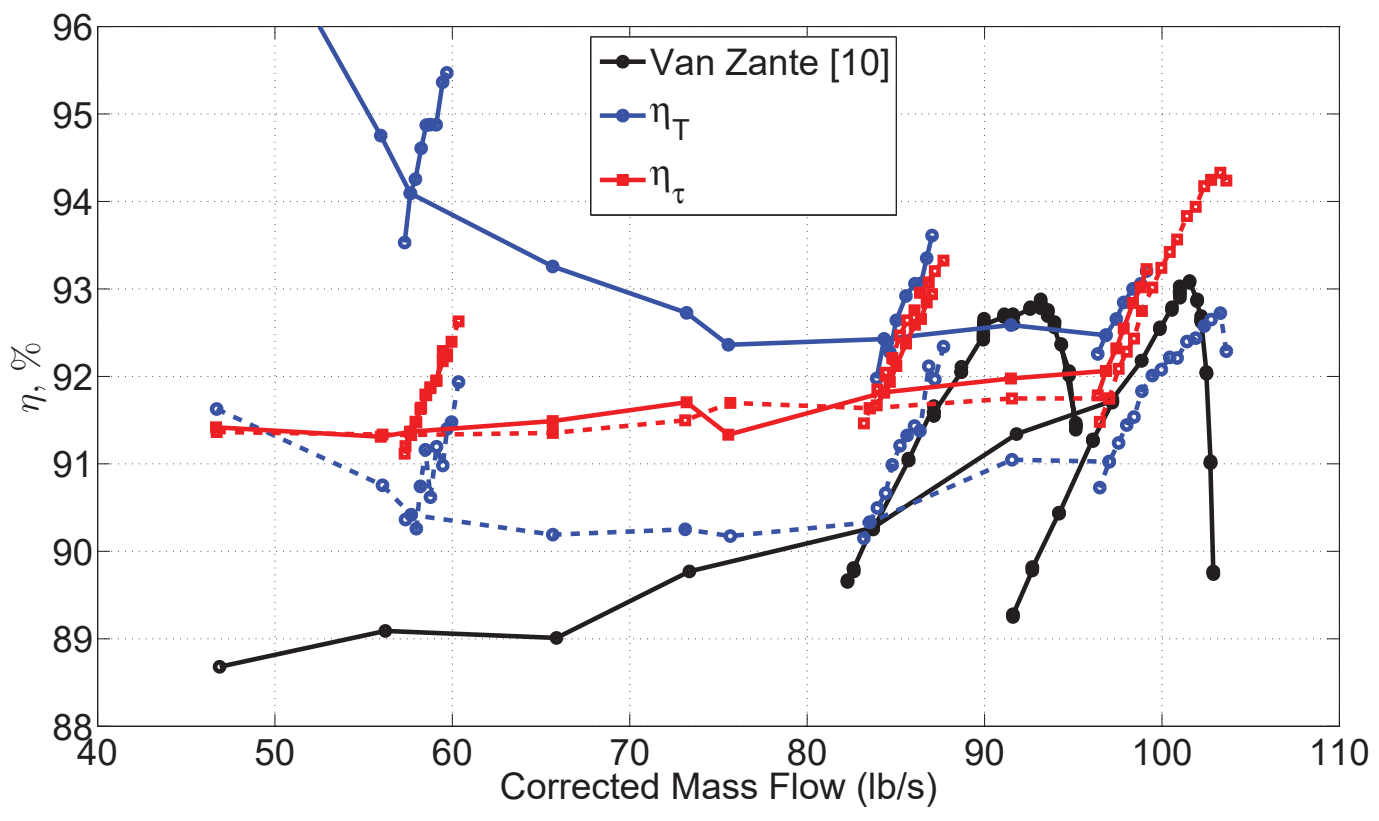

FIGURE 7: HARDWALL FAN EFFICIENCY COMPARISON WITH HISTORICAL DATA FROM VAN ZANTE [10]. DASHED LINES ARE A REPEAT.

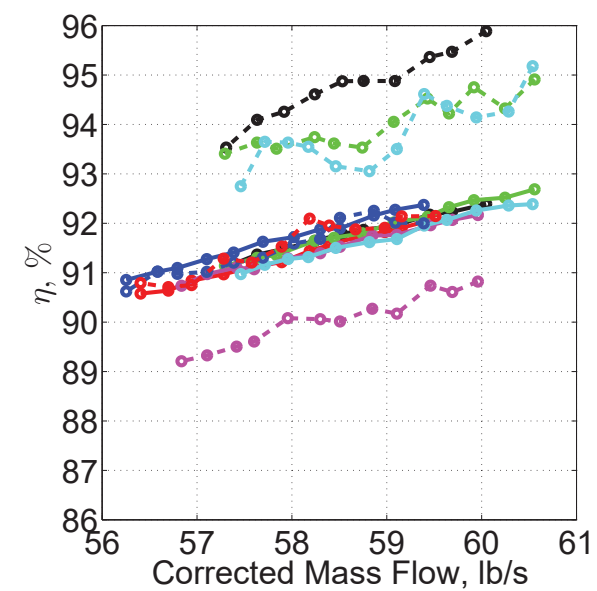

(A) $61.7 \%$ FAN SPEED

$\mathrm{SDR}_{\eta T}=0.75 \%$

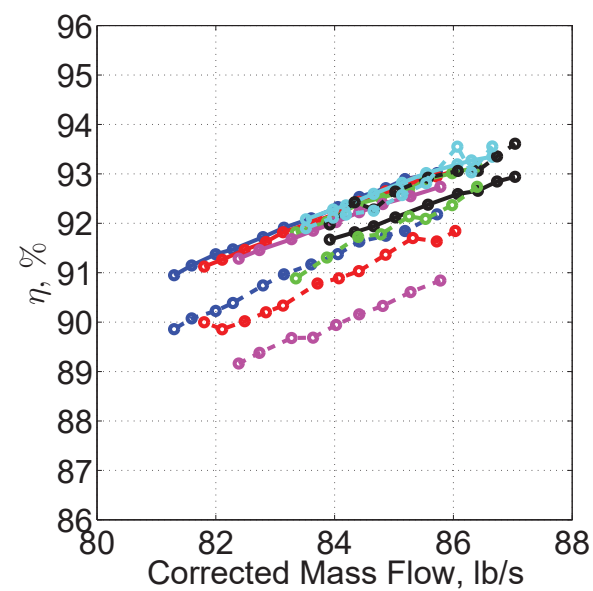

(B) $87.5 \%$ FAN SPEED

$\mathrm{SDR}_{\eta T}=0.52 \%$

$\mathrm{SDR}_{\eta \tau}=0.16 \%$

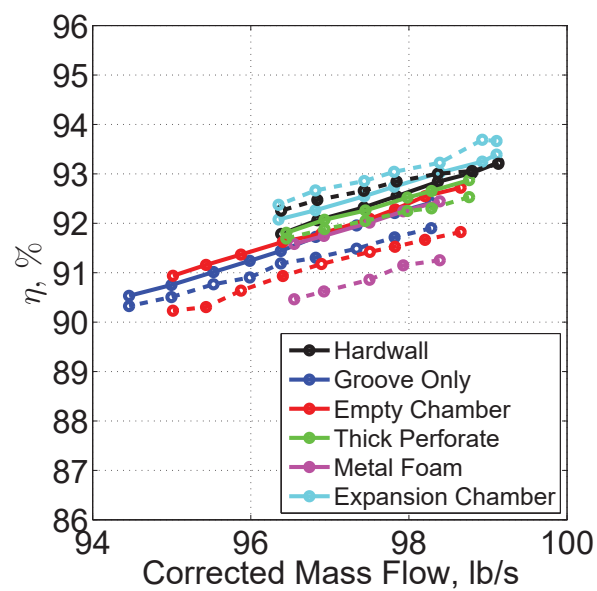

(C) $100 \%$ FAN SPEED

$\mathrm{SDR}_{\eta T}=0.52 \%$

$\operatorname{SDR}_{\eta \tau}=0.17 \%$

FIGURE 8: EFFECT OF FAN CASES CONFIGURATIONS ON EFFICIENCY; SOLID LINES ARE TORQUE BASED $\left(\eta_{\tau}\right)$ AND DASHED LINES ARE TEMPERATURE RAKE BASED $\left(\eta_{T}\right)$. 


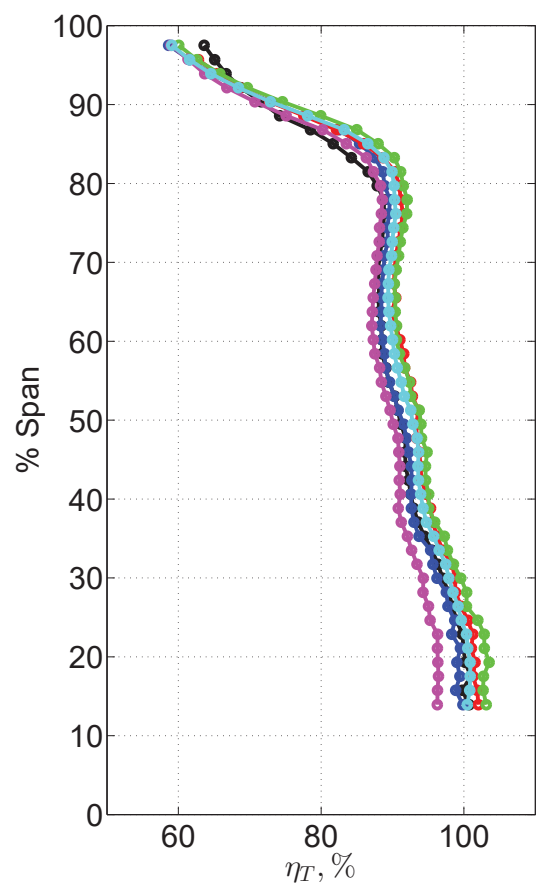

(A) $61.7 \%$ FAN SPEED $S D R_{\eta T}=1.74 \%$

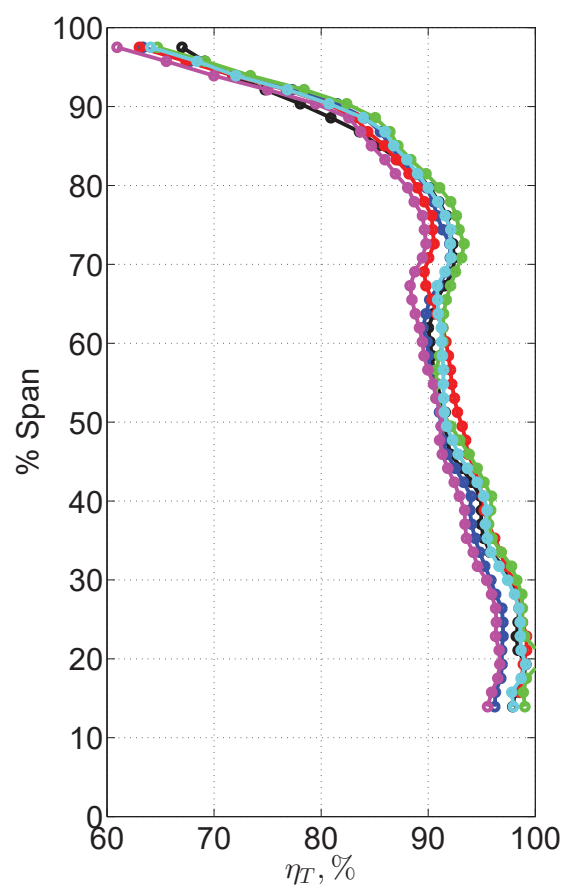

(B) $87.5 \%$ FAN SPEED $S D R_{\eta T}=1.22 \%$

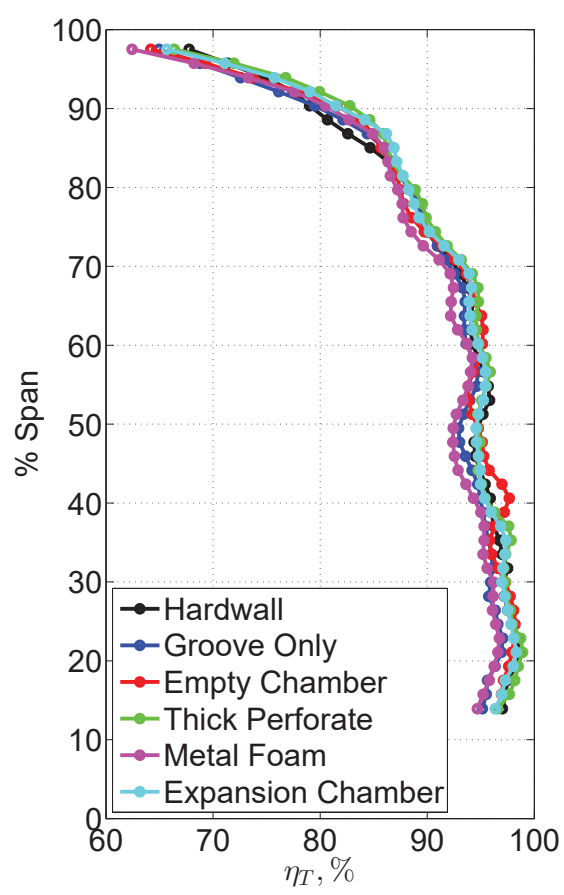

(C) $100 \%$ FAN SPEED $S D R_{\eta T}=0.92 \%$

FIGURE 9: EFFECT OF FAN CASES CONFIGURATIONS ON EFFICIENCY MEASURED BY A TRAVERSING TOTAL PRESSURE AND TOTAL PRESSURE PROBE.

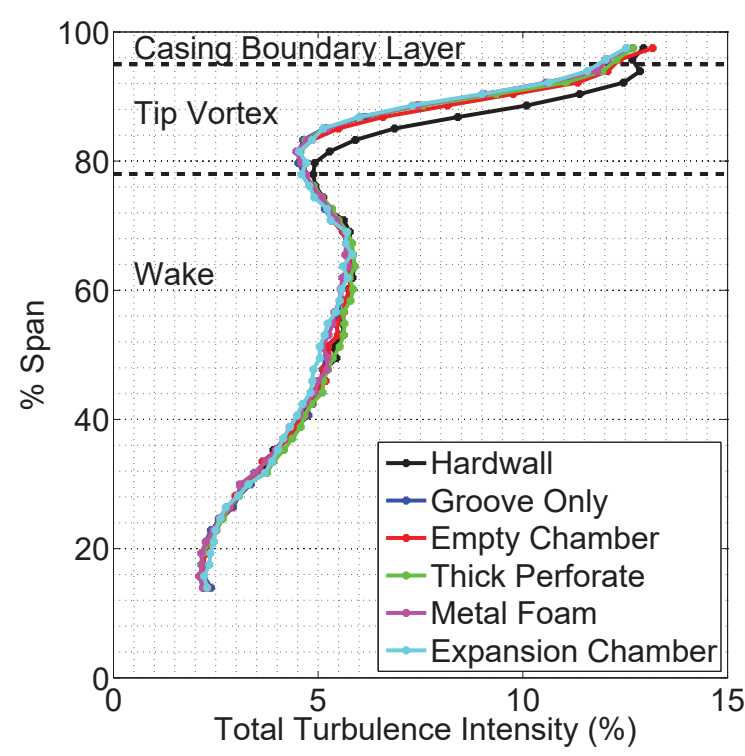

(A)

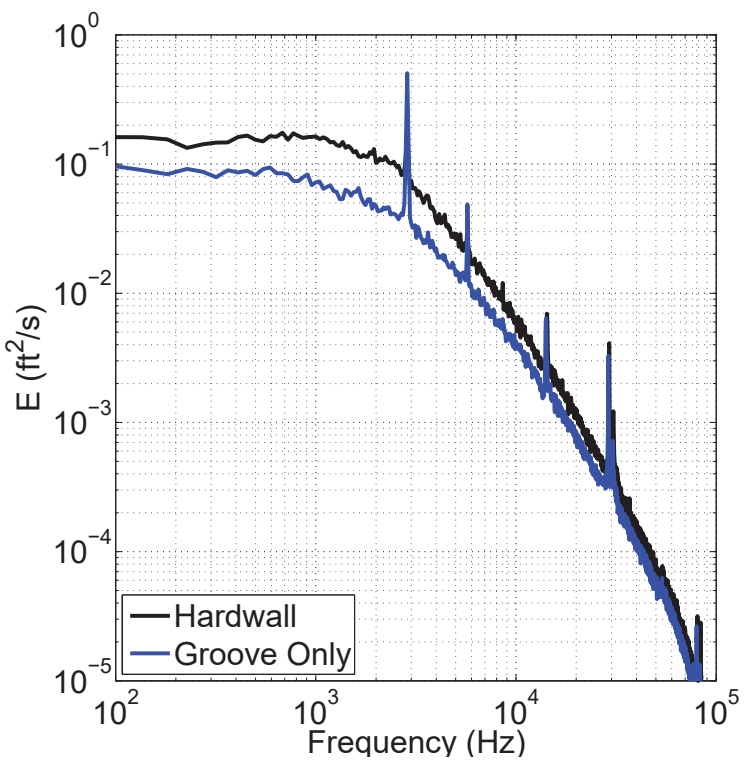

(B)

FIGURE 10: COMPARISONS BETWEEN FAN CASE CONFIGURATIONS AT 61.7\% FAN SPEED OF (A) RADIAL TOTAL TURBULENCE INTENSITY AND (B) THE STREAMWISE TURBULENT ENERGY SPECTRUM AT 87\% SPAN. MEASURED APPROXIMATELY 1 CHORD DOWNSTREAM OF THE ROTOR TRAILING EDGE. 


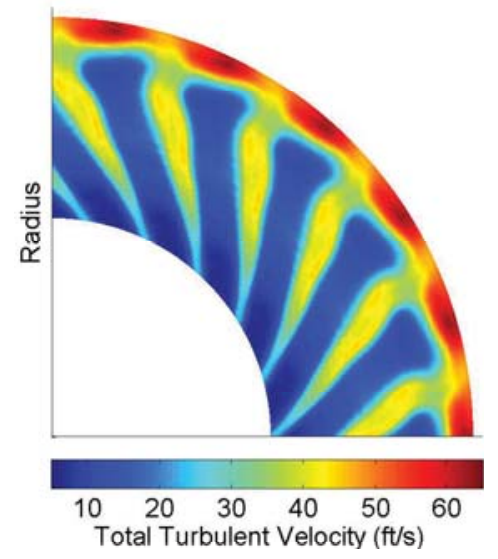

(A) Hardwall

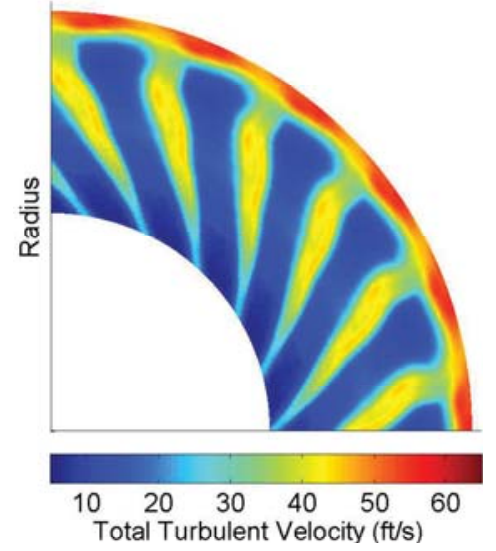

(D) Thick Perforate

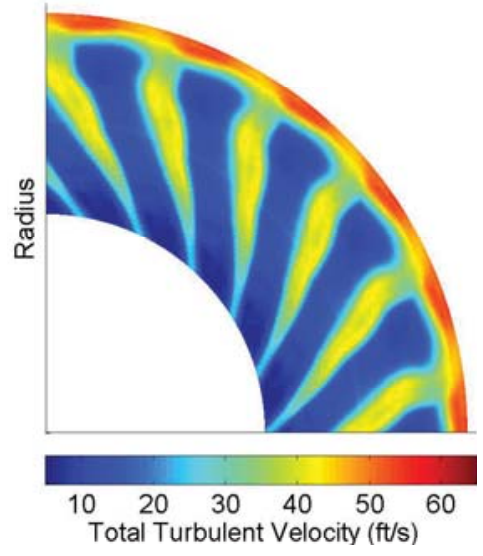

(B) Groove Only

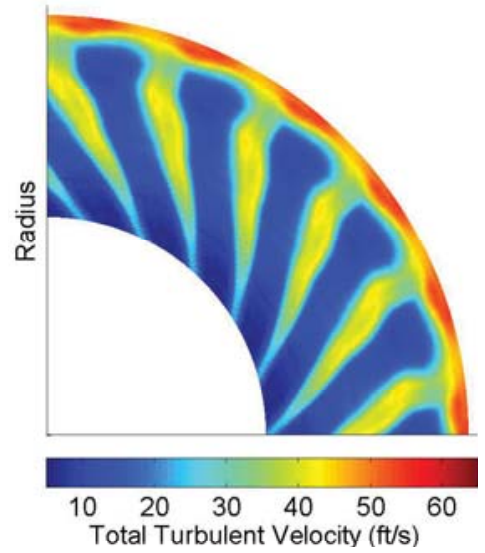

(E) Metal Foam

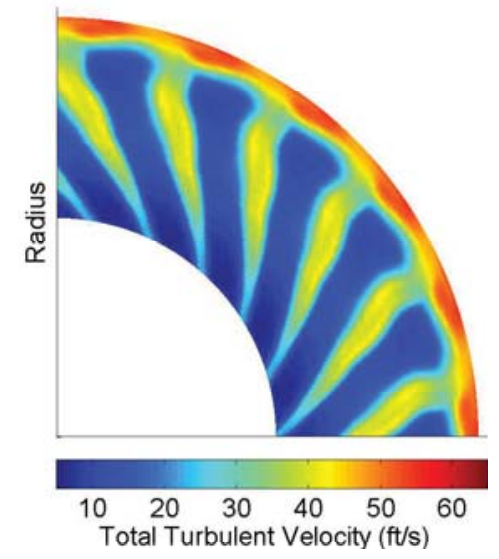

(C) Empty Chamber

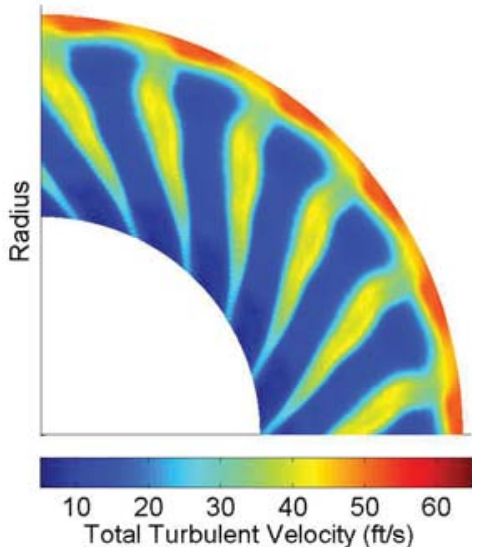

(F) Expansion Chamber

FIGURE 11: EFFECT OF FAN CASES CONFIGURATIONS ON TOTAL TURBULENT VELOCITY CONTOURS AT 61.7\% FAN SPEED. 


\section{REFERENCES}

[1] Thomas, R. H., Burley, C. L., and Nickol, C. L., 2016. "Assessment of the noise reduction potential of advanced subsonic transport concepts for nasa's environmentally responsible aviation project". In 54th AIAA Aerospace Sciences Meeting, AIAA SciTech Forum. American Institute of Aeronautics and Astronautics, Jan.

[2] Sutliff, D. L., Jones, M. G., and Hartley, T. C., 2013. "Highspeed turbofan noise reduction using foam-metal liner overthe-rotor". Journal of Aircraft, 50(5), Sept., pp. 14911503.

[3] Hughes, C., and Gazzaniga, J., 2009. "Effect of two advanced noise reduction technologies on the aerodynamic performance of an ultra high bypass ratio fan". No. AIAA2009-3139 in Aeroacoustics Conferences. American Institute of Aeronautics and Astronautics, May.

[4] Thomas, R. H., Guo, Y., Berton, J., and Fernandez, H., 2017. "Aircraft noise reduction technology roadmap toward achieving the nasa 2035 goal". In 23rd AIAA/CEAS Aeroacoustics Conference, AIAA AVIATION Forum. American Institute of Aeronautics and Astronautics, June.

[5] Guo, Y., Thomas, R. H., Clark, I., and June, J., 2018. "Far term noise reduction roadmap for the mid-fuselage nacelle subsonic transport". In 2018 AIAA/CEAS Aeroacoustics Conference, AIAA AVIATION Forum. American Institute of Aeronautics and Astronautics, June.

[6] Bozak, R., Hughes, C., and Buckley, J., 2013. The aerodynamic performance of an over-the-rotor liner with circumferential grooves on a high bypass ratio turbofan rotor, jun.

[7] Bozak, R. F., Jones, M. G., Howerton, B. M., and Brown, M. C., 2018. "Effect of grazing flow on grooved over-the-rotor acoustic casing treatments". In 2019 AIAA/CEAS Aeroacoustics Conference, no. to be published in AIAA/CEAS Aeroacoustics Conference. American Institute of Aeronautics and Astronautics, May.

[8] Gazella, M., Takakura, T., Sutliff, D. L., Bozak, R., and Tester, B. J., 2017. "Evaluating the acoustic benefits of over-the-rotor acoustic treatments installed on the advanced noise control fan". No. AIAA-2017-3872 in AIAA AVIATION Forum. American Institute of Aeronautics and Astronautics, June.

[9] Bozak, R., and Dougherty, R. P., 2018. "Measurement of noise reduction from acoustic casing treatments installed over a subscale high bypass ratio turbofan rotor". In 2018 AIAA/CEAS Aeroacoustics Conference, AIAA AVIATION Forum. American Institute of Aeronautics and Astronautics, June.

[10] Van Zante, D. E., Podboy, G. G., Miller, C. J., and Thorp, S. A., 2007. "Testing and performance verification of a high bypass ratio turbofan rotor in an internal flow component test facility". No. GT2013-95114.

[11] Hughes, C., Jeracki, R., Woodward, R., and Miller, C.,
2002. "Fan noise source diagnostic test - rotor alone aerodynamic performance results". No. AIAA-2002-2426 in Aeroacoustics Conferences. American Institute of Aeronautics and Astronautics, June.

[12] Hughes, C., Woodward, R., and Podboy, G., 2005. "Effect of tip clearance on fan noise and aerodynamic performance". No. AIAA-2005-2875 in Aeroacoustics Conferences. American Institute of Aeronautics and Astronautics, May.

[13] Bailey, E. E., 1972. "Effect of grooved casing treatment on the flow range capability of a single-stage axial-flow compressor". No. NASA TM-X-2459. NASA.

[14] Hathaway, M. D., 2007. "Passive endwall treatments for enhancing stability". No. NASA TM-2007-214409. NASA.

[15] Lemmon, E. W., Bell, I., Huber, M. L., and McLinden, M. O., 2018. NIST Standard Reference Database 23: Reference Fluid Thermodynamic and Transport PropertiesREFPROP, Version 10.0, National Institute of Standards and Technology.

[16] Smith, N. R., Berdanier, R. A., Fabian, J. C., and Key, N. L., 2015. Reconciling compressor performance differences for varying ambient inlet conditions.

[17] Berdanier, R. A., Smith, N. R., Fabian, J. C., and Key, N. L., 2014. "Humidity effects on experimental compressor performance-corrected conditions for real gases". Journal of Turbomachinery, 137(3), Oct., pp. 031011-031011-10.

[18] Hah, C., 2011. "Steady and unsteady flow effects of circumferential grooves casing treatment in a transonic compressor rotor". No. IGTC-0014.

[19] Amiet, R. K., 1975. "Acoustic radiation from an airfoil in a turbulent stream". Journal of Sound Vibration, 41, Aug., pp. 407-420. 